\title{
Optimized design and experiment of a fully automated potted cotton seedling transplanting mechanism
}

\author{
Xianglei Xue ${ }^{1}$, Lianhao $\mathrm{Li}^{2}$, Chunlin $\mathrm{Xu}^{1 *}$, Enquan $\mathrm{Li}^{1}$, Yujie Wang ${ }^{1}$ \\ (1. College of Engineering, Northeast Agricultural University, Harbin 150030, China; \\ 2. College of Mechanical and Electrical Engineering, Henan Agricultural University, Zhengzhou 450002, China)
}

\begin{abstract}
In order to improve the accuracy and stability of transplanting machine seedling picking, a seedling pick-up mechanism was designed, which was controlled by a controller and driven by brushless DC servo motor. At the same time, the parameters of the seedling manipulator were optimized: the mathematical model for the seedling pick-up mechanism was established. According to the predetermined trajectory requirements, the objective function and constraint conditions were proposed, and then the optimal size was obtained by a multi-objective genetic algorithm. At last, Automatic Dynamic Analysis of Mechanical Systems (ADAMS) software was used to simulate and analyze the kinematics and trajectory of the seedling pick-up mechanism, and the mechanism was tested to verify the effectiveness of the mechanism prototype. The experiments showed that the success rate of seedling picking was $94.32 \%$, the rate of acceptably planted seedlings was $96.67 \%$, and the rate of excellently planted seedlings was $63.48 \%$.
\end{abstract}

Keywords: cotton seedling, transplanting machine, kinematic model, optimized design, test, full automation DOI: $10.25165 /$ j.ijabe.20201304.5317

Citation: Xue X L, Li L H, Xu C L, Li E Q, Wang Y J. Optimized design and experiment of a fully automated potted cotton seedling transplanting mechanism. Int J Agric \& Biol Eng, 2020; 13(4): 111-117.

\section{Introduction}

Compared with direct seeding, cotton transplanting requires $50 \%-70 \%$ fewer seeds, increases yield by $20 \%-34.6 \%$, increases velvet length by $0.3 \mathrm{~mm}$, and improves the grade by $0.2^{[1-3]}$. To promote cotton transplanting, the social demand for high-efficiency potted cotton seedling transplanters has become increasingly urgent.

Cotton transplanting could be divided into bare-root seedling transplantation and potted seedling transplantation, of which bare-root seedling transplantation has a higher degree of mechanization. However, bare-root seedlings have a higher growing cost and are easier to injure than potted seedlings. Potted seedling transplantation lacks relevant models, so potted seedlings are typically manually transplanted. Europe, America and Japan were the first countries to develop automated potted seedling transplanters ${ }^{[4]}$. One representative model is the HD series automated transplanter produced by the Transplant System Company, which performs several series of actions driven by a mechatronics system to complete seedling collection, delivery and planting. The fully automated transplanter made in Japan adopts a push-out seedling separation scheme and utilizes the same seedling delivery and planting methods as those used by the European and

\section{Received date: 2019-08-04 Accepted date: 2020-03-14}

Biographies: Xianglei Xue, $\mathrm{PhD}$ candidate, research interests: design and manufacturing of transplanting equipment, Email: xuexianglei2017@163.com; Lianhao Li, PhD, Associate Professor, research interests: mechanical electrical integration, Email: lianhao8002@126.com; Enquan Li, Master, research interests: design and manufacturing of tillage technology and equipment, Email: 16645132606@163.com; Yujie Wang, Master, research interests: design and manufacturing of tillage technology and equipment, Email: wyj960120@163.com.

*Corresponding author: Chunlin $\mathrm{Xu}, \mathrm{PhD}$, Professor, research interests: design and manufacturing of tillage technology and equipment. College of Engineering, Northeast Agricultural University, Harbin, 150030, China. Tel: +86-451-55191789, Email: 13904656458@163.com.
American models. The above models are expensive and are costly to maintain, which are not suitable traits for use in China ${ }^{[5]}$. Direct seeding is the main method of cotton planting in foreign countries, but there are few reports on automated transplanters for potted cotton seedlings ${ }^{[6,7]}$. A series of studies on automated potted seedling transplantation were carried out by domestic scholars, who used transmission cases to drive the seedling collection mechanism and planting mechanism for transplantation $^{[8-10]}$. The automated transplanting assembly for potted cotton seedlings developed by Huazhong Agricultural University is controlled by a motor-driven hydraulic system. When the frequency of potted seedling throwing is 50 plants $/ \mathrm{min}$, $67 \%$ of the potted seedlings are delivered in a vertical orientation ${ }^{[11]}$. Zhao et al. ${ }^{[12]}$ designed a rotating mechanism for cotton transplanters to pick up potted seedlings, which provides a reference for automated seedling collection of cotton seedlings by transplanting with substrates. Currently, the cotton transplanting machines in domestic and foreign markets are semiautomated and are mostly suitable for bare-root seedling transplantation ${ }^{[13-16]}$.

To meet the requirements of fully automated transplanting of potted cotton seedlings, we proposed a mechanism ${ }^{[17]}$ with an integrated functionality of seedling collection and transplanting. The mechanism is driven by a planetary gear train with noncircular gears and consists of an automated seedling picking mechanism and a duckbilled planting mechanism, which can complete seedling picking, sending, receiving and planting in one cycle. Through the combination of the rotary transplanting mechanism and duckbilled planting mechanism, the proposed device is fast, practical and reliable.

\section{Design requirements and working mechanism}

2.1 Design requirements of potted cotton seedling transplant mechanism

According to agronomic requirements, the potted cotton seedling cultivation period is $30-35 \mathrm{~d}$, the height of the seedling is 
$150-200 \mathrm{~mm}$ and the plant spacing is $350-500 \mathrm{~mm}$. Strong cotton seedlings have a tough stem and an irregularly developed and distributed root system ${ }^{[18]}$. If soil-taking transplantation is adopted, the root system in soil pots will be damaged easily, and the subsequent growth of cotton seedlings will be affected. Xiong Naixin ${ }^{[19,20]}$ conducted an experimental study at Hunan Agricultural University on the mechanical properties of potted cotton seedlings reaching the transplanting age. Their results showed that the minimum tensile strength and maximum pull-out strength of cotton seedlings were $44.128 \mathrm{~N}$ and $4.446 \mathrm{~N}$, respectively. He also crushed the cotton seedling stalks and found that the minimum pressure needed to completely crush the stalks was $418.197 \mathrm{~N}$.

According to the above conclusions, potted cotton seedlings have a certain clamping resistance, and we adopt a transplanting scheme of clipping potted seedlings in this paper. The transplanting mechanism needs to simulate the artificial transplanting action, which has the following specific requirements: 1) The trajectory of the clip tip in the process of collecting seedlings needs to be perpendicular to the potted seedling. 2) The picking arm cannot interfere with the bowl plate while conveying seedlings. 3) The potted seedlings cannot interfere with the planter while throwing seedlings. 4) During the planting process, the absolute trajectory of the planter must maintain an approximately vertical posture at both the entry and excavation stages.

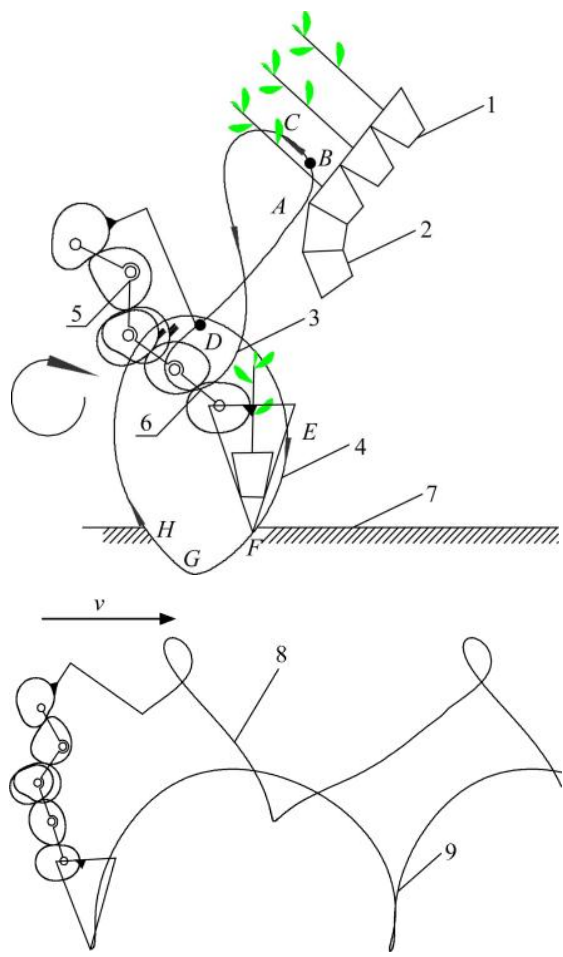

1. Potted seedling 2. Bowl tray 3. Trajectory of seedling collection 4. Planting trajectory 5. Planet frame for seedling collection 6. Planet frame for planting 7 . Ground 8 . Trajectory of seedling collection 9 . Trajectory of planting

Figure 1 Trajectory of fully automated potted cotton seedling transplanting mechanism

Based on the above requirements, the trajectory of the automated potted cotton seedling transplanting mechanism is proposed in this paper. Figure 1 shows that the mechanism rotates clockwise, wherein $A-B-C-D-A$ represents the static trajectory of seedling collection and transportation. The mechanism clamps the cotton seedlings at point $A$ and completely clamps the cotton seedlings at point $B . \quad B C$ is the stage of seedling collection and emergence, and point $D$ is the seedling throwing time. $E-F-G-H-E$ is the static trajectory of seedling grafting and planting. Point $F$ is the time to receive seedlings, $F G$ represents the soil entry process of the planter, the planter opens at point $G$, and $G H$ represents the stage when the planter leaves the soil. The absolute trajectory of the planter is a " $\gamma$ " shape that maintains the vertical motion posture of the planting process.

\subsection{Working principle of transplanting mechanism}

Figure 2 shows that the rotating gear train of the fully automated potted cotton seedling transplant mechanism consists of three meshing noncircular gear trains, which drive the seedling picking arms and duckbilled planter to complete the collecting and planting seedlings.

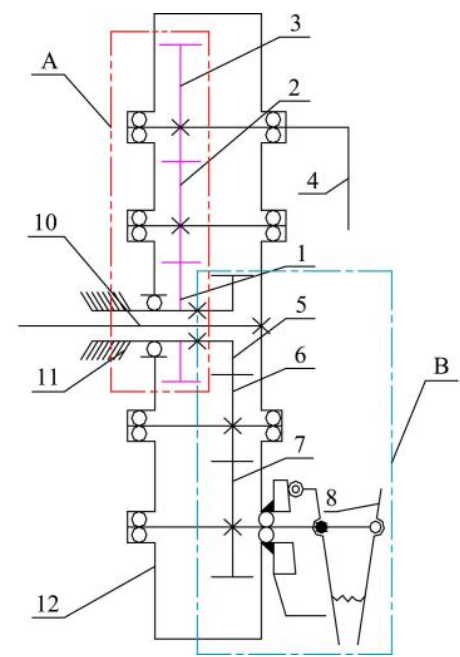

1. Sun wheel for picking seedlings 2. Intermediate wheel for picking seedlings 3. Planetary wheel for picking seedlings 4. Seedling picking arm 5. Sun wheel for seedling planting 6. Intermediate wheel for seedling planting 7. Planetary wheel for seedling planting 8. Duckbilled planter 9. End cam 10. Power input shaft 11. Frame 12. Gearbox A. Planetary gear train for picking seedlings B. Planting planetary gear train

Figure 2 Diagram of integrated fully automated potted cotton seedling transplanting mechanism

Both sun wheel 1 and sun wheel 5 are concentrically fixed to the frame (11) through tooth insertion. Intermediate wheel 2, planetary wheel 3 , intermediate wheel 6 and planetary wheel 7 can rotate around the gearbox (12). The power input shaft (10) is fixed to the gearbox and drives the transplanting mechanism to rotate clockwise. Intermediate wheel 2 engages with sun wheel 1 and planetary wheel 3, and the seedling picking arm (4) is fixed to planetary wheel 3. While the gearbox rotates at a uniform speed, the wheel system of noncircular gears drives the wheel to rotate at an unequal speed. The planetary gear train and seedling picking planetary gear train share the gearbox. Intermediate wheel 6 drives planetary gear 7 . The planter (8) and planetary gear 7 are fixed and rotate unequally with respect to the gearbox. The cam (9) is fixed on the gearbox. The opening and closing of the duckbilled planter are controlled by the relative rotational motion and the reset spring. The fully automated potted cotton seedling transplant mechanism can complete a transplanting operation in one movement cycle.

\section{Kinematic analysis of the transplanting mechanism}

\subsection{Pitch curve shaping method for the noncircular gears}

The planetary gear train with noncircular gears controls the transmission ratio by adjusting the curve equation; it is easy to create concave and convex phenomena in the pitch curve while forming a more complex trajectory. It is difficult to process the 
formed noncircular gear ${ }^{[21,22]}$. In this paper, the Pascal worm line and rotary wheel line ${ }^{[23,24]}$ are used to control the formation of the pitch curve of the seedling picking gear train and the seedling planting gear train, respectively, which enlarges the adjustment range of transmission ratio so that the transplanting mechanism meets the design requirements and avoids serious deformation of a single noncircular gear pitch curve.

\subsection{Establishment of a kinematic model for the transplanting mechanism}

Figure 3 shows that the coordinate system was established with the center of the dynamic input axis as the origin, the horizontal direction as the $X$-axis, and the vertical direction as the $Y$-axis. A kinematic model of the transplanting mechanism was established by taking the counterclockwise direction as the positive direction.

First, the center distances for the seedling picking gear system and seedling planting gear system are determined.

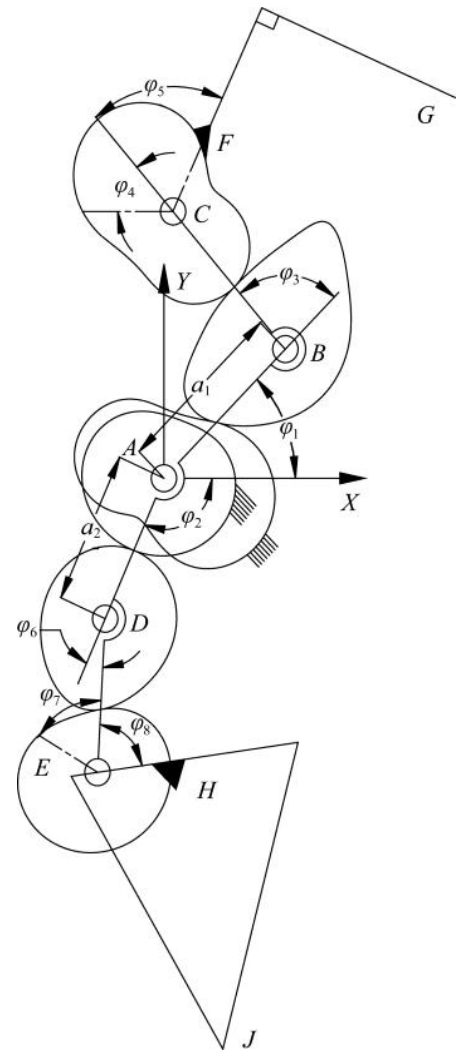

Figure 3 Kinematic diagram of transplanting mechanism

Note that $O O_{1}=a_{1}$ and $O O_{2}=a_{2}$. The speed of the transplanting mechanism was $\omega$. When the gearbox turned $\varphi$ clockwise, the noncircular gear train for the seedling collection was analyzed, and the rotation angle of the gearbox was as follows:

$$
\varphi=\omega t
$$

The absolute motion angle of the seedling planetary frame is as follows:

$$
\varphi_{H}(\varphi)=\varphi_{1}-\varphi
$$

where, $\varphi_{1}$ is the angle of the planetary carriage at the initial installation position relative to the axis counterclockwise, rad.

The rotation angle and absolute rotation angle of the sun wheel relative to the seedling picking planetary carriage are as follows:

$$
\left\{\begin{array}{l}
\alpha_{1}(\varphi)=\varphi \\
\theta_{1}(\varphi)=\varphi_{1}
\end{array}\right.
$$

The rotation angle and absolute rotation angle of the middle wheel for seedling picking relative to the planetary carriage for seedling picking are as follows:

$$
\left\{\begin{array}{l}
\alpha_{2}(\varphi)=\sum_{i=0}^{\varphi-1} \frac{r_{1}(i)}{r_{2}(i)} \cdot\left[\alpha_{1}(i+1)-\alpha_{1}(i)\right] \\
\theta_{2}(\varphi)=\varphi_{H}(\varphi)-\alpha_{2}(\varphi)
\end{array}\right.
$$

where, $r_{1}(i)$ is the radius of the meshing point curve of the sun wheel for the seedling picking gear train, $\mathrm{mm} ; r_{2}(i)$ is the radius of the meshing point curve of the sun wheel for the seedling planting gear train, mm.

$$
r_{2}(i)=a_{1}-r_{1}(i)
$$

The rotation angle and absolute rotation angle of the seedling planetary wheel relative to the seedling planetary frame are as follows:

$$
\begin{gathered}
\left\{\begin{array}{c}
\alpha_{3}(\varphi)=\sum_{i=0}^{\varphi-1} \frac{a_{1}-r_{2}(i)}{r_{2}(i)} \cdot\left[\alpha_{2}(i+1)-\alpha_{2}(i)\right] \\
\theta_{3}(\varphi)=\varphi_{H}(\varphi)-\alpha_{3}(\varphi)+\varphi_{4}+\varphi_{3}+\pi
\end{array}\right. \\
\varphi_{4}=\int_{0}^{\varphi_{3}} \frac{r_{2}(2 \pi-t)}{a_{1}-r_{2}(2 \pi-t)} d t
\end{gathered}
$$

where, $\varphi_{3}$ is the corner of the planetary frame for seedling picking, $\operatorname{rad} ; \varphi_{4}$ is the initial installation angle of the seedling picking planetary wheel caused by the corner of the planetary frame for seedling collection, rad.

The absolute rotation angle of the planting planetary frame is as follows:

$$
\varphi_{H 1}=\varphi_{2}-\varphi
$$

where, $\varphi_{2}$ is the angle of the planting planetary frame in the counterclockwise direction relative to the axis at the initial installation position, rad.

The rotation angle and absolute rotation angle of the planting sun wheel relative to the planting planetary frame are as follows:

$$
\left\{\begin{array}{l}
\alpha_{4}(\varphi)=\varphi \\
\theta_{4}(\varphi)=\varphi_{2}
\end{array}\right.
$$

The rotation angle and absolute rotation angle of the planting intermediate wheel relative to the planting planetary frame are as follows:

$$
\left\{\begin{aligned}
\alpha_{5}(\varphi)=\sum_{i=0}^{\varphi-1} \frac{r_{3}(i)}{r_{4}(i)} \cdot\left[\alpha_{4}(i+1)-\alpha(i)\right] \\
\theta_{5}(\varphi)=\varphi_{H 1}(\varphi)-\alpha_{5}(\varphi) \\
R_{4}(i)=a_{2}-r_{3}(i)
\end{aligned}\right.
$$

where, $r_{3}(i)$ is the radius of the meshing point curve of planting gear system sun wheel, $\mathrm{mm} ; r_{4}(i)$ is the radius of the meshing point curve of planting gear system intermediate wheel, $\mathrm{mm}$.

The rotation angle and absolute rotation angle of the planting planetary gear relative to the planting planetary frame are as follows:

$$
\begin{gathered}
\left\{\begin{array}{c}
\alpha_{6}(\varphi)=\sum_{i=0}^{\varphi-1} \frac{a_{2}-r_{3}(i)}{r_{3}(i)} \cdot\left[\alpha_{5}(i+1)-\alpha_{5}(i)\right] \\
\theta_{6}(\varphi)=\varphi_{H}(\varphi)-\alpha_{5}(\varphi)+\varphi_{7}+\varphi_{6}+\pi
\end{array}\right. \\
\varphi_{7}=\int_{0}^{\varphi_{6}} \frac{r_{3}(2 \pi-t)}{a_{2}-r_{3}(2 \pi-t)} d t
\end{gathered}
$$

where, $\varphi_{6}$ is the planting planetary frame corner, rad; $\varphi_{7}$ is the initial installation angle of the planting planetary gear caused by the corner of the planting planetary frame, rad.

The rotational center of the sun wheel for seedling picking and planting is as follows:

$$
\left\{\begin{array}{l}
x_{A}(\varphi)=( \\
y_{A}(\varphi)=(
\end{array}\right.
$$


The position coordinates of the rotational center of the middle wheel of seedling picking are as follows:

$$
\left\{\begin{array}{l}
x_{B}(\varphi)=a_{1} \cdot \cos \left(\varphi_{H}(\varphi)\right) \\
y_{B}(\varphi)=a_{1} \cdot \sin \left(\varphi_{H}(\varphi)\right)
\end{array}\right.
$$

The position coordinates of the rotational center of the seedling planetary wheel are as follows:

$$
\left\{\begin{array}{l}
x_{C}(\varphi)=x_{B}(\varphi)+a_{1} \cdot \cos \left(\varphi_{H}(\varphi)+\varphi_{3}\right) \\
y_{C}(\varphi)=y_{B}(\varphi)+a_{1} \cdot \sin \left(\varphi_{H}(\varphi)+\varphi_{3}\right)
\end{array}\right.
$$

The position coordinates of the rotational center of the intermediate planting wheel are as follows:

$$
\left\{\begin{array}{l}
x_{D}(\varphi)=a_{2} \cdot \cos \left(\varphi_{H 1}(\varphi)\right) \\
y_{D}(\varphi)=a_{2} \cdot \sin \left(\varphi_{H 1}(\varphi)\right)
\end{array}\right.
$$

The planting planetary wheel rotational center position coordinates are as follows:

$$
\left\{\begin{array}{l}
x_{E}(\varphi)=x_{D}(\varphi)+a_{2} \cdot \cos \left(\varphi_{H 1}(\varphi)+\varphi_{6}\right) \\
y_{E}(\varphi)=y_{D}(\varphi)+a_{2} \cdot \sin \left(\varphi_{H 1}(\varphi)+\varphi_{6}\right)
\end{array}\right.
$$

Then, the coordinates of the inflection point of the seedling picking arm are determined as follows:

$$
\left\{\begin{array}{l}
x_{F}(\varphi)=x_{C}(\varphi)+s \cdot \cos \left(\varphi_{H}(\varphi)+\varphi_{1}+\theta_{3}(\varphi)+\varphi_{5}\right) \\
y_{F}(\varphi)=y_{C}(\varphi)+s \cdot \sin \left(\varphi_{H}(\varphi)+\varphi_{1}+\theta_{3}(\varphi)+\varphi_{5}\right)
\end{array}\right.
$$

where, $s$ is the distance from the rotational center of the planetary wheel to the inflection point $\mathrm{C}$ of the seedling arm, $\mathrm{mm} ; \varphi_{5}$ is the initial installation angle of the seedling picking arm, rad.

The coordinates of the tips used to pinch the seedlings are as follows:

$$
\left\{\begin{array}{l}
x_{G}(\varphi)=x_{F}(\varphi)+L \cdot \cos \left(\varphi_{H}(\varphi)+\varphi_{1}+\theta_{3}(\varphi)+\varphi_{5}-\frac{\pi}{2}\right) \\
y_{G}(\varphi)=y_{F}(\varphi)+L \cdot \sin \left(\varphi_{H}(\varphi)+\varphi_{1}+\theta_{3}(\varphi)+\varphi_{5}-\frac{\pi}{2}\right)
\end{array}\right.
$$

where, $L$ is the distance from the inflection point of the seedling picking arm to the pinching point on the seedling, $\mathrm{mm}$.

The central coordinates of the duckbilled planter are as follows:

$$
\left\{\begin{array}{l}
x_{H}(\varphi)=x_{e}(\varphi)+L_{E H} \cdot \cos \left(\varphi_{H 1}(\varphi)+\varphi_{2}+\theta_{6}(\varphi)+\varphi_{8}\right) \\
y_{H}(\varphi)=y_{e}(\varphi)+L_{E H} \cdot \sin \left(\varphi_{H 1}(\varphi)+\varphi_{2}+\theta_{6}(\varphi)+\varphi_{8}\right)
\end{array}\right.
$$

where, $L_{E H}$ is the distance from planetary wheel center to duckbill center, $\mathrm{mm}$.

The coordinates of tip $J$ of the duckbilled planter are as follows:

$$
\left\{\begin{array}{l}
x_{J}(\varphi)=x_{H}(\varphi)+H \cdot \cos \left(\varphi_{H 1}(\varphi)+\varphi_{2}+\alpha_{6}(\varphi)+\varphi_{8}+\frac{\pi}{2}\right) \\
y_{J}(\varphi)=y_{H}(\varphi)+H \cdot \sin \left(\varphi_{H 1}(\varphi)+\varphi_{2}+\alpha_{6}(\varphi)+\varphi_{8}+\frac{\pi}{2}\right)
\end{array}\right.
$$

where, $H$ is the height of the duckbilled planter, mm.

\section{Parameter optimization and planting process analysis}

\subsection{Optimizing target setting of transplanting mechanism}

According to the agronomic requirements of potted cotton seedling transplantation and the structural characteristics of rotary transplanting mechanisms, the optimization objectives are as follows ${ }^{[25-27]}$ : 1) During the periodic work of the transplanting mechanism, the seedling picking arm must not interfere with the seedling tray; 2) The soil penetration depth of the duckbilled planter should exceed $40 \mathrm{~mm}$; 3) The length of the straight line segment during seedling picking should be greater than $60 \mathrm{~mm}$;
4) The angle while picking seedlings should be between $-5^{\circ}$ and $5^{\circ}$

5) The angle between the movement direction of the splint and the planter must be less than $200^{\circ}$; 6) The angle between the duckbill entry process and the ground must be between $80^{\circ}$ and $100^{\circ}$; 7) The process of duckbill excavation must be between $80^{\circ}$ and $100^{\circ}$; 8) During the periodic operation of the mechanism, the seedling picking arm must not interfere with the duckbilled planter; 9) The gear module of the seedling picking gear train should be greater than $2.5 \mathrm{~mm}$; 10) The gearbox must be more than $20 \mathrm{~mm}$ above ground height; 11) The tip trajectory of the duckbilled planter should be greater than $150 \mathrm{~mm}$; 12) The module of the planting gear train must be more than $2.5 \mathrm{~mm}$; 13) The gap between the bottom of the seedling box and the center of the input shaft must be greater than $30 \mathrm{~mm}$.

\subsection{Development of transplanting mechanism optimization} software

According to the kinematics analysis results of the transplanting mechanism, the functional relationship between each parameter and the optimization objective was established. The optimum range of each optimization objective was determined. Automated optimum design software for potted cotton seedling transplanting was developed based on Visual Basic 6.0. Human-computer interaction can be realized in the optimization process, and operators can adjust parameters by observing the feedback results of optimization objectives, which greatly reduces the difficulty of optimization and shortens the design cycle.

The optimization software interface is shown in Figure 4. Through this software, a set of structural design parameters that meet the requirements of potted cotton seedling transplantation are obtained. The parameters of the planetary gear train for potted cotton seedling transplanting are taken as follows: $a_{1}=33.9, b_{1}=4.17$, $c_{1}=-5.8, d_{1}=-0.96, e_{1}=9.2, f_{1}=-6.1, a_{2}=21.5, b_{2}=37 \mathrm{~mm}, c_{2}=-9.3$, $d_{2}=12, e_{2}=-19.3, f_{2}=3.77, \alpha_{1}=270, \alpha_{2}=66, \alpha_{3}=-88, \alpha_{4}=90, \alpha_{5}=144$, and $z_{1}=21$. The planetary gear train parameters are as follows: $a_{11}=-59.1, b_{11}=26, c_{11}=-46.9, d_{11}=17.7, e_{11}=1, e_{22}=-0.5, f_{11}=8.43$, $f_{22}=2.94, g_{11}=-0.749, \varphi_{1}=108, \varphi_{2}=-3, \varphi_{3}=-180, \varphi_{4}=183$, ss $=80$, $h h=114$, and $z_{2}=21$. The mechanism parameters are as follows: $L_{1}=69, L_{2}=118, x_{g}=166, y_{g}=126$, gama $=56, H_{1}=400$, di $=-173$, $l=150, R=70$, and $N=60$. The optimized target values are as follows: $m_{1}=5 \mathrm{~mm}, m_{2}=40.7 \mathrm{~mm}, m_{3}=83 \mathrm{~mm}, m_{4}=4.3^{\circ}, m_{5}=32.3^{\circ}$, $m_{6}=93^{\circ}, m_{7}=83^{\circ}, m_{8}=10.6 \mathrm{~mm}, m_{9}=2.68 \mathrm{~mm}, m_{10}=25 \mathrm{~mm}, m_{11}=$ $195 \mathrm{~mm}, m_{12}=2.54 \mathrm{~mm}$, and $m_{13}=433 \mathrm{~mm}$.

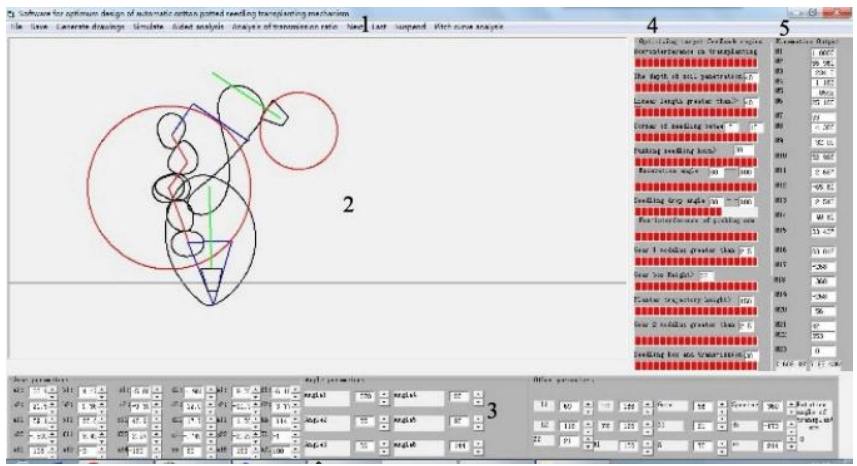

1. Menu bar 2. Drawing area 3. Parameter tuning area 4. Target optimization display area 5. Result output zone

Figure 4 Optimization software interface

\subsection{Analysis of planting process}

The most important index for measure the performance of transplanters is the upright degree of potted seedlings after transplanting, followed by operational efficiency ${ }^{[28]}$. In this paper, 
a duckbilled planter was used as the research object to analyze the planting process. The transplanting process of the transplanting mechanism is as follows: the transplanter begins to enter the soil until the seedling is completely separated from the duckbilled planter, and the transplanting mechanism needs to meet the specific trajectory and posture requirements.

In this paper, the absolute trajectory curve of the tip and the absolute rotation angle of the transplanter obtained by optimization are studied. The planting process of the transplanting mechanism is analyzed in Figure 5. The absolute trajectory of the tips of the transplanter is a "Y" shape, which is approximately a straight line in the planting process. It is helpful to reduce the resistance of duckbill to soil entry and excavation. Moreover, to ensure the upright degree of potted seedlings after transplanting, the absolute rotation angle of the planter is expressed by the variation in the angle between the central point of the planter and the duckbill tip and the ground. Figure 6 shows that the rotation angle of the planter slightly varies near $90^{\circ}$ when the gearbox angle is $0-56^{\circ}$ and $326^{\circ}-360^{\circ}$. Therefore, during the planting process, the planter maintains its vertical position with the ground in these positions, and the results of mechanism optimization satisfy the vertical degree of seedlings after transplanting.

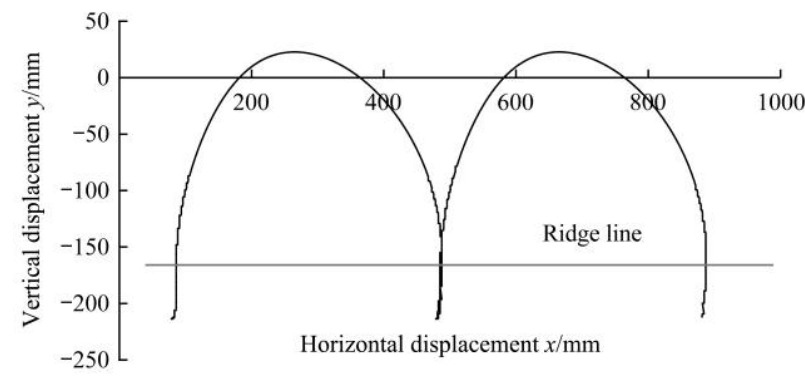

Figure 5 Absolute trajectory of the duckbilled planter

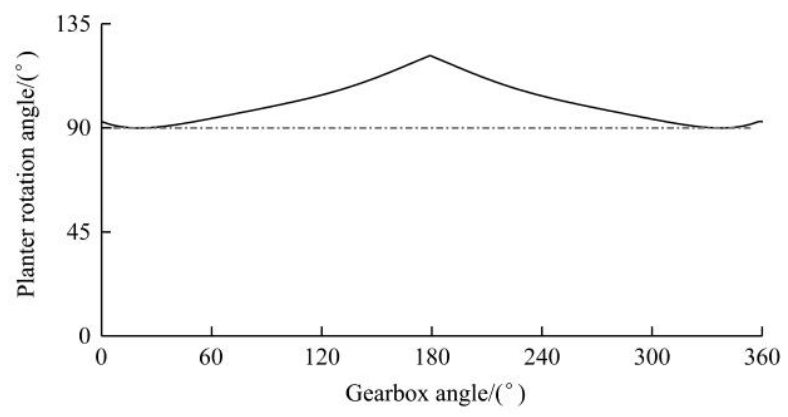

Figure 6 Absolute angle of the duckbilled planter

\section{Virtual simulation and physical prototype test}

\subsection{Virtual simulation test}

The structure design of the fully automated potted cotton seedling transplanting mechanism was carried out, and the resultant three-dimensional model was imported into ADAMS software for simulation testing. The absolute trajectory of the transplanting mechanism was analyzed. The results showed that software optimization was basically consistent with the simulation test.

The rationality and correctness of the mechanism design preliminarily verify the final structural parameters.

\subsection{Verification of high-speed photographic trajectory}

According to the final structural parameters, the three-dimensional structure model of the transplanting mechanism was established, and parts of the transplanting mechanism were rapidly manufactured via $3 \mathrm{D}$ printing technology. To ensure the success rate of transplanting, metal seedling clamps and push rods were designed and processed, and a physical prototype was assembled. A multifunctional transplanting testbed developed by the research group was used to carry out the bench operation test, in which the tester was driven by a motor (model Y100L1-4). The static trajectory between the tip of the clamp and the tip of the planter is recorded with high-speed photography, as shown in Figure 8 , the results show that the trajectory of the software optimization is basically the same as that of the physical prototype, which further verifies the correctness of the structural design of the transplanting mechanism.
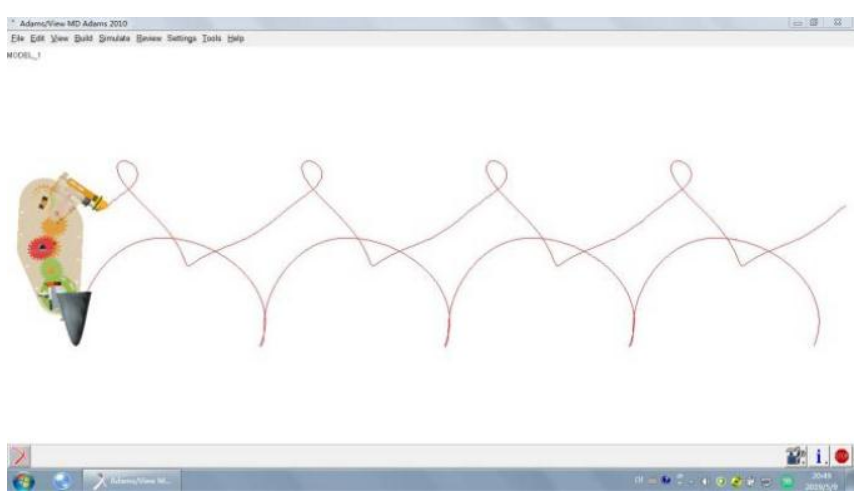

Figure 7 Absolute trajectory of $400 \mathrm{~mm}$ plant spacing

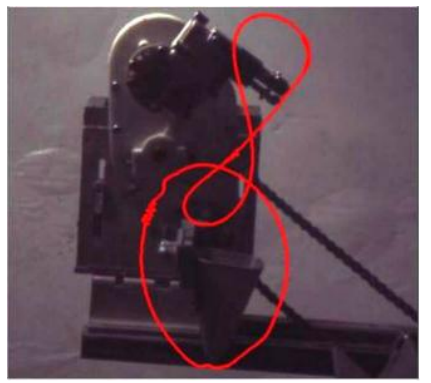

Figure 8 Trajectory of the physical prototype

\subsection{Virtual simulation and physical prototype test}

As the key stage of automated transplanting mechanism operation, the process of throwing and transplanting seedlings determines the success or failure of transplantation. In this paper, kinematic analyses of the process and physical prototype test bench were performed. High-speed photography technology was used to mark the locus of the cotton seedling gravitational center in the process of throwing and grafting seedlings, verifying the accuracy of the action of seedling throwing and seedling grafting.

Because the cotton seedling was obliquely thrown under its gravity after being acted on by the initial impulse of the seedling pusher, the initial velocity of the seedling in the horizontal direction and vertical direction was set. The angle between the closing displacement direction and horizontal direction was set. The horizontal distance from the seedling center of gravity to the center of the planter was set at the moment of seedling throwing, and the horizontal displacement of the seedling center of gravity was set as the vertical position of the cotton seedling center of gravity. The movement process was analyzed.

$$
\begin{gathered}
x=v_{1} \cdot t \\
y=v_{2} \cdot t-\frac{1}{2} g t^{2} \\
\tan \alpha=\frac{2 v_{2}-g \cdot t}{2 v_{1}}
\end{gathered}
$$

When the cotton seedlings fell into the planter, the process of throwing and grafting seedlings took a certain amount of time, which can be expressed as follows: 


$$
t=\frac{s}{v_{1}}
$$

Because $\mathrm{s}$ was smaller in the Equation, the ratio of $\mathrm{s}$ to $v_{1}$ was close to 0 when $v_{1}$ was maximal. Hence, the time used during the process of seedling throwing and seedling grafting is very short. Substituting Equation (26) into Equation (25) shows that the angle between the direction of cotton seedling movement and the horizontal direction was approximately fixed; therefore, the cotton seedling moved along a straight line.

Considering the reliability of 3D-printed parts, the speed of the mechanism was set to $30 \mathrm{r} / \mathrm{min}$. In this paper, the shape of the pot body of the trial pot seedling is consistent with the geometry of the hole plate. The trajectory of the potted cotton bowl geometric center is shown in Figure 9. Potted cotton seedlings were successfully dropped into the duckbilled planter along an approximately straight line. The correctness of the kinematic analysis was verified, which showed that the optimization results met the design requirements of throwing and receiving seedlings.

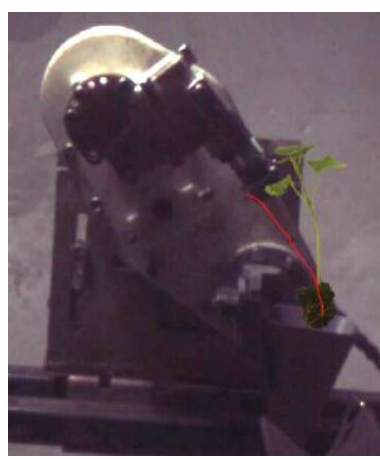

Figure 9 Trajectory of the cotton seedlings

5.4 Experiments on seedling picking and planting

Potted cotton seedlings were cultivated in the plant factory laboratory of the College of Engineering at Northeast Agricultural University. The Lumianyan 18 cotton variety was selected for seeds. The horticultural nutrient soil produced by Xuzhou Yaode Chemical Co., Ltd. which contained several materials, including perlite, vermiculite, peat, and organic matter, was selected as the seedling raising medium. The original soil was a 1:1 ratio of Northeast black soil and soil matrix. A soft bowl plate was selected for seedling cultivation. The number of points per bowl plate was 120. The size of the bowl plate was $40 \mathrm{~mm} \times 40 \mathrm{~mm}$ at the mouth of the upper point, $25 \mathrm{~mm} \times 25 \mathrm{~mm}$ at the mouth of the lower point, and the depth of the mouth of the hole was $36 \mathrm{~mm}$. Seedling refining was carried out two to three days before transplanting, the water content of the bowl was $21.8 \%$.

The bud stage grew in the closed nursery, and the temperature was set to $25^{\circ} \mathrm{C}-30^{\circ} \mathrm{C}$. We used light-emitting diode (LED) fill light for $12 \mathrm{~h}$ of even illumination every day. At the seedling stage, the seedlings were moved to a light plant factory. The seedlings were raised for $35 \mathrm{~d}$, and we finished the seedling refining two to three days before transplanting.

Experiments were carried out in the Agricultural Mechanization Test Center of the College of Engineering at Northeast Agricultural University. The rotation speed of the transplanting institution was $30 \mathrm{r} / \mathrm{min}$, the plant spacing was $400 \mathrm{~mm}$, and the moving speed of the soil trough was $0.2 \mathrm{~m} / \mathrm{s}$ during the test. A total of 354 cotton seedlings were used for the test. The test indicators were measured by the success rate of seedling picking, and the planting effect was measured by the degree of uprightness. The angle between the cotton seedling stalk and the soil groove ridge was between $70^{\circ}$ and $110^{\circ}$; note that $45^{\circ}-70^{\circ}$ or $110^{\circ}-135^{\circ}$ is considered acceptable, whereas angles outside of these ranges are unacceptable ${ }^{[28]}$. The test results are shown in Table 1.

Table 1 Test results

\begin{tabular}{|c|c|c|c|c|c|c|}
\hline $\begin{array}{l}\text { Series of seedling } \\
\text { plug trays }\end{array}$ & $\begin{array}{l}\text { Number of } \\
\text { seedlings }\end{array}$ & Seedlings picked & $\begin{array}{l}\text { Success rate of } \\
\text { picking } / \%\end{array}$ & Seedlings planted & $\begin{array}{l}\text { Acceptably planted } \\
\text { seedlings/\% }\end{array}$ & $\begin{array}{l}\text { Excellently planted } \\
\text { seedlings } / \%\end{array}$ \\
\hline 1 & 118 & 109 & 92.31 & 108 & 96.55 & 62.52 \\
\hline 3 & 120 & 115 & 95.83 & 113 & 97.83 & 64.58 \\
\hline Average & 118 & 111 & 94.32 & 110 & 96.67 & 63.48 \\
\hline
\end{tabular}

The test results show that the transplanting mechanism meets the requirements of seedling picking, but the rate of excellently planted seedlings was low, indicating that the planting effect was poor. The reasons for the falling cotton seedlings were as follows: 1) The content of the seedling substrate in the carcass is too high, resulting in poor sputum formation. The soil mites are easily damaged after the seedlings are taken, which affects the degree of uprightness; 2) There is vibration in the test bench; 3) The best transplant rate was not found during the test.

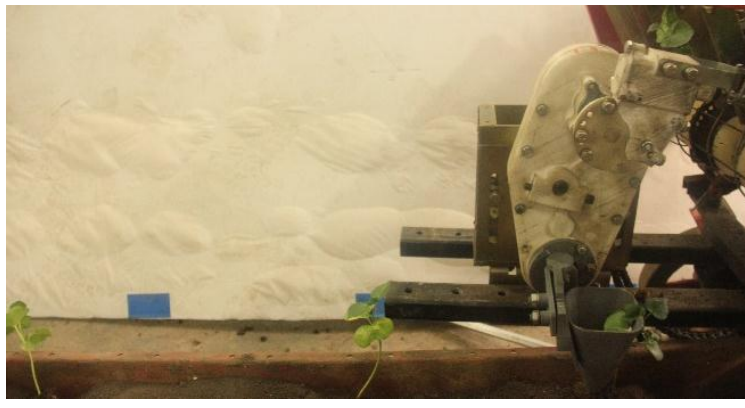

Figure 10 Test of seedling picking and transplanting

\section{Conclusions}

1) Transplanting potted cotton seedlings requires fewer seeds, provides higher yield and offers higher quality than direct seeding. The paper aimed to develop a more efficient and universal potted cotton seedling auto transplantation technique, an automated transplanting mechanism was designed with an integrated functionality of seedling picking and transplanting.

2) A fully automated potted cotton seedling transplant mechanism was proposed. The seedling picking arm and the duckbilled planter were driven by a set of slewing mechanisms, and the action of picking seedlings, feeding seedlings and planting seedlings could be completed in one cycle. The mechanism has a highly efficient, lightweight, practical, reliable, simple structure with a low design cost. This mechanism lays a research foundation for automated transplanting of cotton seedlings and transplanting of other dry crops such as pepper and eggplant, which has practical application value.

3) Aiming at the design difficulties of multi-objective, multi-parameter, strong coupling of planetary gear trains with 
noncircular gears, a kinematic model of the transplanting mechanism was established. According to the agronomic requirements of potted cotton seedling transplanting, the design goal was optimized, and an objective function was established. The optimization design software was based on Visual Basic 6.0, from which a set of structural parameters was obtained that met the requirements of automated cotton seedling transplanting. The above conclusions provide a theoretical basis for the development of a rotary transplanting mechanism in many fields.

4) According to the optimization results, the planting process of the transplanting mechanism was analyzed. The results showed that the absolute rotation angle of the planter in the soil and excavation stage slightly varied near $90^{\circ}$, which satisfied the requirements of the orthostatic degree after transplanting and subsequently met the requirements of high-speed potted seedling transplanting. The physical prototype was developed, and an ADAMS virtual simulation test and a high-speed photography track verification were carried out, which showed that the software optimization, virtual test and high-speed photography track were basically the same, which verified the correctness of the mechanism design.

5) The potted cotton seedlings were cultivated, and the transplanting mechanism test bench was established, which was used to analyze the kinematic model of potted cotton seedlings in the process of feeding and receiving seedlings. The movement track of cotton seedlings in the process of seedling projection and seedling receiving was determined with high-speed photography. The accuracy of seedling feeding and seedling receiving was verified through an experiment in which the frequency of seedling collection was 30 plants/min: the success rate of the seedling collection was $94.32 \%$, the success rate of seedling planting was $96.67 \%$, and the rate of excellently planted seedlings was $63.48 \%$.

\section{Acknowledgements}

This research was supported by the National Natural Science Foundation of China (Grant No. 51775104).

\section{[References]}

[1] Cao Y L, Chen Y, Lu S M, Yang L, Ke X S, Tu Q J, et al. Review on cotton seeding transplanting technology. China Cotton, 2015; 42(1): 12-14, 18. (in Chinese)

[2] Che Y B, Tang Y Z, Ji C L. Progress and prospect of cotton seedling raising technology in China. China Cotton, 2002; 29(12): 2-4. (in Chinese)

[3] Ke L, Lü F Q, Xiong H. Main growing seedlings and transplanting techniques of cotton production. Jiangxi Cotton, 2013; 35(2): 11-15. (in Chinese)

[4] Yu X X, Zhao Y, Chen B C, Zhou M L, Zhang H. Current situation and prospect of transplanter. Transactions of the CSAM, 2014; 45(8): 44-53. (in Chinese)

[5] Jin X, Cheng Q, Zhao B, Ji J T, Li M Y. Design and test of 2ZYM-2 potted vegetable seedlings transplanting machine. Int J Agric \& Biol Eng, 2020; 13(1): 101-110.

[6] Konosuke T. Development of fully automatic vegetable transplanter. Japan Agriculture Research Quarterly, 2000; 34: 21-28.

[7] Jin X, Li D Y, Ma H, Ji J T, Zhao K X, Pang J. Development of single row automatic transplanting device for potted vegetable seedlings. Int $\mathrm{J}$ Agric \& Biol Eng, 2018; 11(3): 67-75

[8] Hu J P, Zhang C D, Wang L Z, Han L H. Design and experiment on automatic greenhouse seedling transplanting machine. Transactions of the CSAM, 2016; 47(S1): 149-154.

[9] Yu G H, Chen Z W, Zhao Y, Sun L, Ye B L. Study on vegetable plug seedling pick-up mechanism of planetary gear train with ellipse gears and incomplete non-circular gear. Journal of Machanical Engineering, 2012; 48(13): 32-39. (in Chinese)

[10] Yu J P. Optimization design and experiments of automatic transplanting mechanism for vegetable pot-seedling. Master dissertation. Hangzhou: Zhejiang Sci-Tech University, 2017; 76p. (in Chinese)

[11] Wang H L. Design and experiment study on key component of cotton transplanter. Master dissertation. Wuhan: Huazhong Agricultural University, 2017; 78p. (in Chinese)

[12] Zhao X, Shen M, Chen J N, Dai L. Kinematic analysis and virtual experiment of rotary pick-up mechanism on cotton transplanter. Transactions of the CSAE, 2014; 30(8): 13-20. (in Chinese)

[13] Jin X. Research on automatic transplanting technology and device for vegetable plug seedling. PhD dissertation. Beijing: China Agricultural University, 2014; 115p. (in Chinese)

[14] Li B, Gu S, Chu Q, Yang Y L, Xie Z J, Fan K J, et al. Development of transplanting manipulator for hydroponic leafy vegetables. Int J Agric \& Biol Eng, 2019; 12(6): 38-44.

[15] Li G W. Design and research on taking and feeding seedling mechanism for cotton seedlings transplanting mechanism. Master dissertation. Changsha: Hunan Agricultural University, 2013; 91p. (in Chinese)

[16] Zhao Y, Liu X, Xue X L, Zhang W X, Shan Y Y, Zhou M L. Optimal design and experiment of potted eggplant seedling transplanting mechanism. Transactions of the CSAM, 2018; 49(5): 152-160. (in Chinese)

[17] Xu C L, Xue X L, Zhang W X, Shan Y Y, Xie J T. Combination mechanism of seedling picking-up and planting assembly with non-circular gear planetary gear system. 2019; China ZL 201811064900.7.

[18] Mao S C, Han Y C. The picture shows that cotton substrate seedling raising and transplanting. Beijing: Jindun Press, 2014; pp.34-36. (in Chinese )

[19] Xiong N X. Design and research on cotton seedlings transplanting mechanism. Master dissertation. Changsha: Hunan Agricultural University, 2011; 76p. (in Chinese)

[20] Zong W Y, Huang X M, Xu A Y, Fan X W, Huang X C. Bending and shearing characteristics of cotton seedling stem. Transactions of the CSAE, 2012; 28(S2): 118-124.

[21] $\mathrm{Wu} \mathrm{X} \mathrm{T,} \mathrm{Wang} \mathrm{G} \mathrm{H.} \mathrm{Non-circular} \mathrm{gear} \mathrm{and} \mathrm{non-uniform} \mathrm{speed} \mathrm{ratio}$ drive. Beijing: Machinery Industry Press, 1997; 355p. (in Chinese)

[22] Zhao Y. Analysis and synthesis of agricultural machinery. Beijing: Machinery Industry Press, 2009; 331p. (in Chinese)

[23] Chen B C. The research and optimization design on automatic potted-seedling transplanter of cycloid gear trains in up and field. Master dissertation. Harbin: Northeast Agricultural University, 2014; 89p. (in Chinese).

[24] Song Z C. Design and optimization of rice seedling transplanter mechanism based on pascal spiral gear. Master dissertation. Harbin: Northeast Agricultural University, 2015; 80p. (in Chinese)

[25] Ministry of Agriculture of the People's Republic of China. Beijing: Technical Specification for Cotton production in the Yangtze River Basin, 2007; NY/T 1292/2007.

[26] Zhou M L. Mechanism analysis and optimal design of high-speed rice pot seedling transplanting mechanism with bezier gears. Master dissertation. Hangzhou: Zhejiang Sci-Tech University, 2014; 95p. (in Chinese)

[27] Zhao Y, Zhang W X, Xin L, Xie J T, Xue X L, Shan Y Y. Design and experiment of extensible potted tomatoes seedling transplanting mechanism. Transactions of the CSAM, 2019; 50(1): 105-112. (in Chinese)

[28] Chen J N, Wang B H, Zhang X, Ren G Y, Zhao X. Kinematics modeling and characteristic analysis of multi-linkage transplanting mechanism of pot seeding transplanter with zero speed. Transactions of the CSAE, 2011; 27(9): 7-12. (in Chinese)

[29] Yu G H, Liao Z P, Xu L H, Zhao P, Wu C Y. Optimization design and test of large spacing planetary gear train for vegetable pot-seedling planting mechanism. Transactions of the CSAM, 2015; 46(7): 38-44. (in Chinese) 